Research paper

\title{
New arrangements on several species subcomplexes of Triatoma genus based on the chromosomal position of ribosomal genes (Hemiptera - Triatominae)
}

\author{
Sebastián Pita ${ }^{\text {a }}$, Pedro Lorite ${ }^{\text {b }}$, Julieta Nattero ${ }^{\mathrm{c}, 1}$, Cleber Galvão ${ }^{\mathrm{d}}$, Kaio C.C. Alevi ${ }^{\mathrm{e}}$, Simone C. Teves ${ }^{\mathrm{f}, \mathrm{g}}$, \\ Maria T.V. Azeredo-Oliveira ${ }^{\text {e }}$, Francisco Panzera ${ }^{\mathrm{a}, *}$ \\ a Sección Genética Evolutiva, Facultad de Ciencias, Universidad de la República, Montevideo, Uruguay \\ b Departamento de Biología Experimental, Área de Genética, Universidad de Jaén, Jaén, Spain

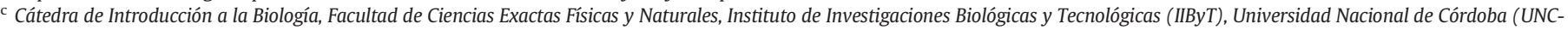 \\ CONICET), Córdoba, Argentina \\ ${ }^{\mathrm{d}}$ Laboratório Nacional e Internacional de Referência em Taxonomia de Triatomíneos, Instituto Oswaldo Cruz - FIOCRUZ, Rio de Janeiro, Brazil

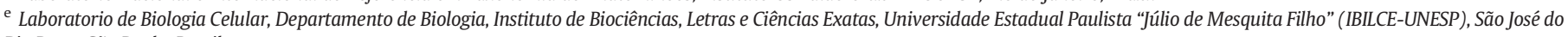 \\ Rio Preto, São Paulo, Brazil \\ ${ }_{\mathrm{f}}^{\mathrm{L}}$ Laboratório Interdisciplinar de Vigilância Entomológica em Diptera e Hemiptera (LIVEDIH), Instituto Oswaldo Cruz/Fundação Oswaldo Cruz, Rio de Janeiro, Brazil \\ g Programa de Pós-Graduação em Biologia Animal, Universidade Federal Rural do Rio de Janeiro, Rio de Janeiro, Brazil
}

\section{A R T I C L E I N F O}

\section{Article history:}

Received 14 February 2016

Received in revised form 18 May 2016

Accepted 19 May 2016

Available online 28 May 2016

\section{Keywords:}

Triatominae

Chagas disease vectors

Holocentric chromosomes

Location changes of rDNA clusters

FISH

\begin{abstract}
A B S T R A C T
The hemipteran subfamily Triatominae includes 150 blood-sucking species, vectors of Chagas disease. By far the most specious genus is Triatoma, assembled in groups, complexes and subcomplexes based on morphological similarities, geographic distribution and genetic data. However, many molecular studies questioned the species integration of several subcomplexes as monophyletic units. In triatomines, chromosomal position of major ribosomal DNA (rDNA) loci is extremely variable but seems to be species-specific and an evolutionary conserved genetic trait, so that closely related species tend to have ribosomal clusters in the same chromosomal location. Considering that the autosomal position as the ancestral character for all heteropteran species, including triatomines, we suggest that the movement of rDNA loci from autosomes to sex chromosomes rapidly established reproductive barriers between divergent lineages. We proposed that the rDNA translocation from the autosomes to the sex chromosomes restrict reproductive compatibility and eventually promote speciation processes. We analyzed the chromosomal position of $45 \mathrm{~S}$ rDNA clusters in almost all species of the matogrossensis, rubrovaria, maculata and sordida subcomplexes. The fluorescent in situ hybridization results are discussed considering the available genetic data and we proposed new arrangements in the species that constitute each one of these subcomplexes.
\end{abstract}

(c) 2016 Elsevier B.V. All rights reserved.

\section{Introduction}

Triatomines are blood-sucking insects which are well known for being vectors of Chagas disease or American trypanosomiasis. This illness is considered as the most serious human parasitic disease of Latin America with around 6-7 million infected people (WHO, 2016). In the absence of vaccines or adequate drugs for large-scale treatment, the reduction of disease burden critically depends on the control of vector

\footnotetext{
* Corresponding author at: Sección Genética Evolutiva, Facultad de Ciencias, Universidad de la República, Iguá 4225, 11400 Montevideo, Uruguay.

E-mail address: fcopanzera@gmail.com (F. Panzera).

1 Current address: Laboratorio de Eco-Epidemiología, Departamento de Ecología, Genética y Evolución, Facultad de Ciencias Exactas y Naturales, Universidad de Buenos Aires (IEGEBA-UBA-CONICET), Buenos Aires, Argentina.
}

transmission by triatomines. Given so, a correct taxonomic identification of species is extremely important for successful control campaigns.

The subfamily Triatominae includes 150 species in 15 to 18 genera, being by far the more frequent the Triatoma genus with 73 species (Galvão and Paula, 2014). Historically, several authors have assembled the Triatoma species in different groups and complexes based on their external characters and the genitalia of both sexes (Ryckman, 1962; Usinger et al., 1966; Lent and Wygodzinsky, 1979; Carcavallo et al., 2000). Currently, the most accepted grouping was proposed by Schofield and Galvão (2009), which subdivides Triatoma species in groups, complexes and subcomplexes based on morphological similarities, geographic distribution and genetic data. Although complex and subcomplexes are not considered as taxonomic categories for the International Code of Zoological Nomenclature (ICZN, 1999) its application on Triatominae attempt to reveal phylogenetic relationships. This 
means that a subcomplex species represents a monophyletic unit including evolutionarily closed related species derived from a common ancestor. The establishment of monophyletic assemblages is very important in order to infer possible common attributes related to their biology, epidemiological significance and response to control interventions (Schofield and Galvão, 2009). Within Triatoma genus, these authors recognized 14 monophyletic units, most of them supported with different genetic analyses. However, new studies based on comparisons of DNA sequences question the species integration of several subcomplexes. These questions mainly involves almost all Triatoma subcomplexes from South America, such as brasiliensis (Gardim et al., 2014), maculata (Dos Santos et al., 2007; Carbajal de la Fuente et al., 2008), matogrossensis (Gardim et al., 2013; Teves et al., 2016) and rubrovaria (Noireau et al., 2002; Almeida et al., 2009; Justi et al., 2014).

Triatominae subfamily species, similar to other heteropterans have holocentric chromosomes, i.e. chromosomes with diffuse or non-localized centromeres (Hughes-Schrader and Schrader, 1961). The absence of a primary constriction and their homogeneity in their autosomal number limited comparative and evolutionary chromosomal studies (Panzera et al., 2010). As a taxonomic tool, banding techniques application has been a valuable for karyotypic differentiation and to detect cryptic species, particularly in sordida subcomplex (Panzera et al., 1997, 2015). Recent application of fluorescent in situ hybridization (FISH) to determine the chromosomal position of major ribosomal clusters shows that this trait is species-specific and also with a striking inter-specific variability, revealing an extraordinary dynamics of change in the genomes during the evolution in this insect group (Panzera et al., 2012). Ribosomal ribonucleic acid (rRNA) is the main structural and catalytic component of the ribosome, being essential for protein synthesis in all living organisms. It is indispensable for cell viability and is one of only a few gene products present in all cells. In eukaryotes, the genes encoding ribosomal RNA (rDNA) are present in multiple copies, arranged as clusters and located in one or more chromosomes, named nucleolar chromosomes. Typically, each repeat unit of the major ribosomal cluster (45S rDNA) contains three regions encoding the $18 \mathrm{~S}, 5.8 \mathrm{~S}$ and 28S rRNAs.

In a wide range of organisms, including fungi, animals and plants, the location, size and degree of repetition of the basic repeat unit are highly variable. However, the nucleotide sequences of the coding regions are evolutionarily highly preserved by concerted evolution and they are frequently used to develop DNA probes that allow the chromosome location of the rDNA loci by FISH (reviewed in Richard et al., 2008). In different insect groups, such as Coleoptera, Diptera, Hymenoptera, Lepidoptera and Orthoptera, the distribution of these conserved rDNA clusters can be apply for the establishment of physical maps with phylogenetic and evolutionary goals (Hirai et al., 1996; Proença et al., 2005; Roy et al., 2005; Cabrero and Camacho, 2008; Cabral de Mello et al., 2011; Šíchová et al., 2013).

In Heteroptera order, FISH analyses of a hundred species from 38 genera showed that the rDNA clusters are restricted to one or two loci per haploid genome. The chromosomal position is extremely variable; on a pair of autosomes (exceptionally 2), on m-chromosomes, on one or two sex chromosomes or simultaneously on a pair of autosomes and the $\mathrm{X}$ chromosome. The most predominant location is on one autosomal pair, recorded in species with different chromosome numbers and sex chromosome systems, involving eight of ten studied families including the most ancient groups (Grozeva et al., 2015), being considered as an ancestral character of the Heteroptera order. In spite of that ribosomal loci are regularly inherited by Mendelian fashion, changes in the position of rDNA loci are often originated by chromosomal rearrangements such as fusions, fissions or translocations. In some ants and heteropteran species, these changes may imply modifications in the chromosome number (Hirai et al., 1996; Bressa et al., 2009). Howev$\mathrm{er}$, in Triatominae, given that the number of autosomes remains almost unaffected (almost all species have 20 autosomes), we can rule out that these chromosomal rearrangements are responsible for variation of
rDNA position. Inter-chromosomal mobility of rDNA by other mechanisms such as ectopic recombination and transposition is frequently reported in several insect groups (Cabrero and Camacho, 2008; Nguyen et al., 2010; Cabral de Mello et al., 2011) that could be also the origin of the rDNA location changes observed in Heteroptera (Panzera et al., 2012). In triatomines, chromosomal position of rDNA loci seems to be an evolutionary conserved genetic trait, so that closely related species tend to have the ribosomal genes in the same chromosomal location (Panzera et al., 2012, 2015).

In the current paper, we analyzed the 45S rDNA clusters chromosomal position in almost all species of the matogrossensis, rubrovaria, maculata and sordida subcomplexes, using an 18S rDNA probe isolated from Triatoma infestans. Our FISH results are discussed considering genetic data available and we proposed new arrangements in the species that constitute each one of these subcomplexes.

\section{Materials and methods}

In this paper we compared the $45 \mathrm{~S}$ rDNA clusters chromosomal location in 21 of the 25 recognized species of matogrossensis, rubrovaria, maculata and sordida subcomplexes, ten of them described here for the first time (Table 1). About previously reported species, we improve our analysis including new populations. The four misplaced species (Triatoma deanorum, Triatoma limai, Triatoma oliveirai, and Triatoma arthurneivai) were not analyzed because of the great difficulty to collect and keep them alive in insectariums (Noireau et al., 2002). Geographical origin, number of individuals analyzed and results about the chromosome location of ribosomal clusters are detailed on Table 1, including previous FISH data.

FISH was carried out using squashed gonad preparations. The gonads were extracted from living adult insects and fixed in ethanol-acetic acid (3:1). FISH procedure was applied using as probe an $18 \mathrm{~S}$ rDNA fragment of 807-bp isolated from T. infestans from Uruguay as described by Panzera et al. (2012). Chromosome slides were examined under a Nikon Eclipse 80i microscope and the images were obtained with a DS-5McU2 digital camera. For each specimen, at least 20 cells in meiotic (metaphase I, II or diplotene) or mitotic divisions were analyzed to determine 45S rDNA clusters chromosomal location. Images were processed with the Adobe Photoshop® software.

\section{Results}

All species from matogrossensis, rubrovaria, maculata and sordida subcomplexes present the same diploid chromosome number of 22 chromosomes, constituted by 20 autosomes plus two sex chromosomes (XY in males and XX in females). In all species, the Y chromosome presents an intermediate size and always appears C-heterochromatic.

The 45S rDNA cluster has 1 or 2 chromosome loci per haploid genome, showing three location patterns: on one autosomal pair (14 species) (Fig. 1A, B and C), on the $X$ and $Y$ chromosomes ( 5 species) (Fig. 1D and $\mathrm{E}$ ) and on the $\mathrm{X}$ chromosome (2 species) (Fig. 1F). Each analyzed species presented only one rDNA location pattern; intraspecific variation was not observed. In species that show the ribosomal clusters on both sex chromosomes, the X chromosome signal is much more intense than that observed in the Y chromosome (Fig. 1E), except in T. jurbergi which both sex chromosomes have similar signal intensity (Fig. 1D). In all cases, the hybridization signals were located in a terminal or subterminal chromosomal position. FISH results are summarized in Table 1, including new and previous data.

Considering the subcomplexes until now recognized (Table 1), all rubrovaria subcomplex species are homogenous in their ribosomal clusters chromosomal location, presenting the rDNA signals on an autosomal pair (Fig. 1A). On the contrary, matogrossensis, maculata and sordida subcomplexes include species with rDNA clusters in different chromosomes. Matogrossensis and maculata subcomplex species present two ribosomal patterns: some species with 45S rDNA on an 
Table 1

Geographical origin of analyzed species and chromosomal location of 45S rDNA clusters by fluorescent in situ hybridization (FISH), according to the subcomplexes proposed by Schofield and Galvão (2009). Between brackets we included the number of individuals analyzed. LNIRTT = Laboratório Nacional e Internacional de Referencia em Taxonomia de Triatomíneos, Instituto Oswaldo Cruz, Rio de Janeiro, Brazil; LIVEDIH = Laboratório Interdisciplinar de Vigilância Entomológica em Diptera e Hemiptera, Instituto Oswaldo Cruz, Rio de Janeiro, Brazil. CE $=$ Ceará; $\mathrm{GO}=$ Goias, $\mathrm{MG}=$ Minas Gerais; $\mathrm{MS}=$ Mato Grosso do Sul; MT = Mato Grosso; ND = not determined RS = Rio Grande do Sul; RO $=$ Roraima; $\mathrm{SP}=$ São Paulo, $\mathrm{TO}=$ Tocantins; $\mathrm{D}=$ domestic; $\mathrm{P}=$ peridomestic; $\mathrm{S}=$ sylvatic.

\begin{tabular}{|c|c|c|}
\hline Species & Geographical origin & $\begin{array}{l}45 S \text { rDNA } \\
\text { location }\end{array}$ \\
\hline \multicolumn{3}{|c|}{ Rubrovaria subcomplex } \\
\hline T. carcavalloi & São Jerônimo, RS, Brazil. LNIRTT. [2] & $\begin{array}{l}\text { One autosomal } \\
\text { pair }^{\text {b }}\end{array}$ \\
\hline \multirow[t]{2}{*}{ T. circummaculata } & Cerro Largo, Uruguay. S. [2] & $\begin{array}{l}\text { One autosomal } \\
\text { pair }^{\text {d }}\end{array}$ \\
\hline & Vila São Jerónimo, RS, Brazil. LNIRTT. [2] & $\begin{array}{l}\text { One autosomal } \\
\text { pair }^{\mathrm{d}}\end{array}$ \\
\hline T. klugi & Nova Petrópolis, RS, Brazil. LNIRTT. [2] & $\begin{array}{l}\text { One autosomal } \\
\text { pair }^{\text {d }}\end{array}$ \\
\hline \multirow[t]{2}{*}{ T. rubrovaria } & Artigas, Uruguay. S. [2] & $\begin{array}{l}\text { One autosomal } \\
\text { pair }^{\text {b }}\end{array}$ \\
\hline & $\begin{array}{l}\text { ND. Araraquara (SP) \& LNIRTT insectaries. } \\
{[10]}\end{array}$ & $\begin{array}{l}\text { One autosomal } \\
\text { pair }^{\text {a }}\end{array}$ \\
\hline T. pintodiasi & Caçapava do Sul, RS, Brazil. LNIRTT. [2] & $\begin{array}{l}\text { One autosomal } \\
\text { pair }^{\mathrm{d}}\end{array}$ \\
\hline \multicolumn{3}{|c|}{ Matogrossensis subcomplex } \\
\hline T. baratai & Corumbá, MS, Brazil. LNIRTT. [2] & $\begin{array}{l}\text { One autosomal } \\
\text { pair }^{\text {d }}\end{array}$ \\
\hline \multirow[t]{2}{*}{ T. costalimai } & Posse, GO, Brazil. LNIRTT. [2] & $\begin{array}{l}\text { One autosomal } \\
\text { pair }^{\mathrm{d}}\end{array}$ \\
\hline & Aurora de Tocantins, TO, Brazil. LIVEDIH. [2] & $\begin{array}{l}\text { One autosomal } \\
\text { pair }^{\mathrm{d}}\end{array}$ \\
\hline T. guazu & Barra do Garças, MT, Brazil. LNIRTT. [3] & $\begin{array}{l}\text { One autosomal } \\
\text { pair }^{\mathrm{d}}\end{array}$ \\
\hline T. jatai & Paranã, TO, Brazil. LIVEDIH. [3] & $\begin{array}{l}\text { One autosomal } \\
\text { pair }^{\mathrm{d}}\end{array}$ \\
\hline \multirow[t]{2}{*}{ T. williami } & Fazenda Nova, GO, Brazil. LNIRTT. [2] & $\begin{array}{l}\text { One autosomal } \\
\text { pair }^{\mathrm{d}}\end{array}$ \\
\hline & Barra do Garças, MT, Brazil. LNIRTT. [2] & $\begin{array}{l}\text { One autosomal } \\
\text { pair }^{\mathrm{d}}\end{array}$ \\
\hline T. jurbergi & Alto Garças, MT, Brazil. LNIRTT. [3] & $\begin{array}{l}\mathrm{X} \& \mathrm{Y} \\
\text { chromosomes }^{\mathrm{d}}\end{array}$ \\
\hline \multirow[t]{2}{*}{ T. matogrossensis } & Serra das Arenas, MT, Brazil. LNIRTT. [3] & $\begin{array}{l}\mathrm{X} \& \mathrm{Y} \\
\text { chromosomes }^{\mathrm{b}}\end{array}$ \\
\hline & $\begin{array}{l}\text { ND. Araraquara (SP) \& LNIRTT insectaries. } \\
\text { [11] }\end{array}$ & $\begin{array}{l}\mathrm{X} \& \mathrm{Y} \\
\text { chromosomes }^{\mathrm{a}}\end{array}$ \\
\hline T. vandae & Rondonópolis, MT, Brazil. LNIRTT. [3] & $\begin{array}{l}\mathrm{X} \& \mathrm{Y} \\
\text { chromosomes }^{\mathrm{b}}\end{array}$ \\
\hline \multicolumn{3}{|c|}{ Maculata subcomplex } \\
\hline \multirow[t]{2}{*}{ T. maculata } & Boa Vista, RO, Brazil. P. [2] & $\begin{array}{l}\mathrm{X} \& \mathrm{Y} \\
\text { chromosomes }^{\mathrm{b}}\end{array}$ \\
\hline & Bolivar, RO, Venezuela. LNIRTT. [2] & $\begin{array}{l}\mathrm{X} \& \mathrm{Y} \\
\text { chromosomes }^{\mathrm{d}}\end{array}$ \\
\hline \multirow[t]{2}{*}{$\begin{array}{l}\text { T. } \\
\text { pseudomaculata }\end{array}$} & Sobral, CE, Brazil. LNIRTT. [2] & $\begin{array}{l}\text { One autosomal } \\
\text { pair }^{\text {b }}\end{array}$ \\
\hline & Alem Paraiba, MG, Brazil. S. [2] & $\begin{array}{l}\text { One autosomal } \\
\text { pair }^{\text {d }}\end{array}$ \\
\hline \multirow[t]{2}{*}{ T. wygodzinsky } & São João da Boa Vista, SP, Brazil. S. [2] & $\begin{array}{l}\text { One autosomal } \\
\text { pair }^{\text {b }}\end{array}$ \\
\hline & $\begin{array}{l}\text { Espírito Santo do Pinhal, SP, Brazil. LNIRTT. } \\
\text { [2] }\end{array}$ & $\begin{array}{l}\text { One autosomal } \\
\text { pair }^{\mathrm{d}}\end{array}$ \\
\hline \multicolumn{3}{|c|}{ Sordida subcomplex } \\
\hline $\begin{array}{l}\text { T. sordida } \\
\text { Argentina }\end{array}$ & $\begin{array}{l}\text { Populations from Argentina, Bolivia \& } \\
\text { Paraguay. D, P, S. [29] }\end{array}$ & $\begin{array}{l}\mathrm{X} \& \mathrm{Y} \\
\text { chromosomes }^{\mathrm{c}}\end{array}$ \\
\hline $\begin{array}{l}\text { T. sordida sensu } \\
\text { stricto }\end{array}$ & $\begin{array}{l}\text { Populations from Brazil, Bolivia \& Paraguay. } \\
\text { D, P. [34] }\end{array}$ & $\begin{array}{l}\mathrm{X} \\
\text { chromosome }^{\mathrm{b}, \mathrm{c}}\end{array}$ \\
\hline T. garciabesi & $\begin{array}{l}\text { Populations from Argentina, Bolivia \& } \\
\text { Paraguay. P, S. [39] }\end{array}$ & $\begin{array}{l}\text { X } \\
\text { chromosome }^{\mathrm{b}, \mathrm{c}}\end{array}$ \\
\hline \multirow[t]{3}{*}{ T. patagonica } & 9 de julio, Santa Fe, Argentina. P. [4] & $\begin{array}{l}\text { One autosomal } \\
\text { pair }^{\mathrm{d}}\end{array}$ \\
\hline & Mitre, Santiago del Estero, Argentina. P. [4] & $\begin{array}{l}\text { One autosomal } \\
\text { pair }^{\mathrm{d}}\end{array}$ \\
\hline & San Martin, San Luis, Argentina. P. [1] & One autosomal \\
\hline
\end{tabular}

Table 1 (continued)

\begin{tabular}{lll}
\hline Species & Geographical origin & $\begin{array}{l}\text { 45S rDNA } \\
\text { location }\end{array}$ \\
\hline & Utracan, La Pampa, Argentina, P. [3] & $\begin{array}{l}\text { pair }^{\mathrm{d}} \\
\text { One autosomal } \\
\text { pair }^{\mathrm{d}}\end{array}$ \\
& Avellaneda, Rio Negro, Argentina, P. [3] & $\begin{array}{l}\text { One autosomal } \\
\text { pair }^{\mathrm{d}}\end{array}$ \\
& Populations from Argentina \& Bolivia. S. [24] & One autosomal \\
T. guasayana & & pair $^{\mathrm{c}}$
\end{tabular}

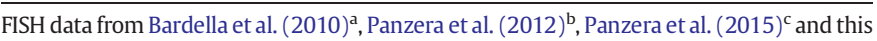
paper $^{\text {d. }}$.

autosomal pair (Fig. 1B), while other carry them on both sex chromosomes (X and Y) (Fig. 1D). Sordida subcomplex species have three ribosomal patterns: on an autosomal pair (Fig. 1C), on both sex chromosomes (Fig. 1E) or on one sex chromosome (X chromosome) (Fig. 1F).

\section{Discussion}

\subsection{Chromosomal location of rDNA clusters as taxonomic marker}

In the 47 Triatomini tribe species currently studied, including ten species here described for the first time, the most frequent location of the rDNA is on one autosomal pair (30 species), usually the largest one, so it could be considered as ancestral for this group. The movement of the ribosomal clusters from autosomes to one ( 8 species) or both sex chromosomes ( 7 species) would be a secondary change, so the location of rDNA loci on sex chromosomes should be considered as an apomorphic character. Since the location of the rDNA loci on one or both sex chromosomes is observed in phylogenetically distant triatomini groups (Dipetalogaster, Eratyrus, Mepraia and several Triatoma species), it is likely that the transfer of rDNA loci from autosomes to sex chromosomes occurred several times during the evolution of this group. Analysis of rDNA loci in Triatomini suggests that each species tend to fix its chromosomal position (character species-specific), so that groups with a common ancestry tend to have the same chromosomal location for rDNA loci.

\subsection{Changes of location of rDNA clusters as an isolation mechanism and promoter of speciation}

Such as observed in other insects, the movements of rDNA clusters from autosomal to sex chromosomal positions could alter the dynamics of gene recombination as well as the gene flow, genetic differentiation and speciation (Sætre et al., 2003). The genes residing on the X chromosome present a very different environment than autosomal genes in terms of gene expression and natural selection (Vicoso and Charlesworth, 2006). Recombination rates vary widely depending on the genomic position (autosomes or sex chromosomes) and the linkage with genes under selection. Since the sex chromosomes in male triatomines are asynaptic and achiasmatic (Solari, 1979), their rates of homologous recombination are reduced by half for the $\mathrm{X}$ chromosomes (which occurs only in females) and to virtually zero for the Y chromosome. In addition, the hemizygosity of the $\mathrm{X}$ chromosome in males will greatly increase the selection of recessive mutations, differentiating thus the rate of mutational changes between the autosomes and sex chromosomes. This can result in faster adaptive evolution of X chromosomes (the faster X effect) (Kaiser and Bachtrog, 2010). As the result of reduced recombination, genetic barriers to gene flow may arise rapidly between populations which fixed sex chromosomal variants. Similar as suggested in lepidopteran speciation (Šíchová et al., 2013), the reduced recombination of sex chromosomes enable the accumulation of genetic incompatibilities and leads to divergence and speciation in triatomines. 

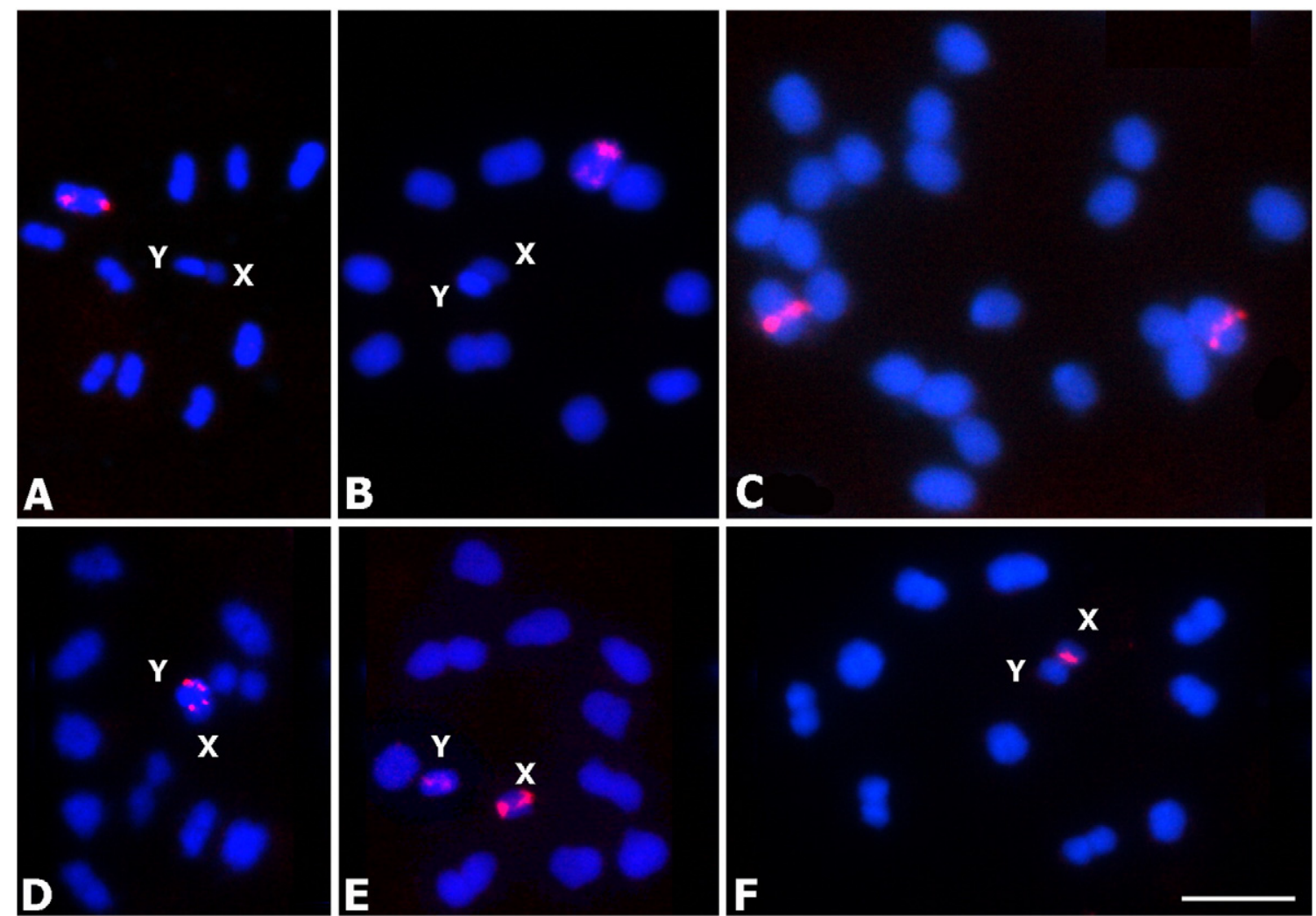

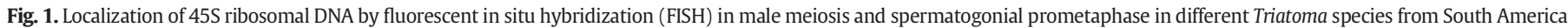

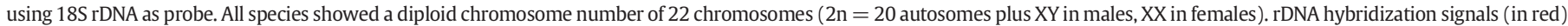

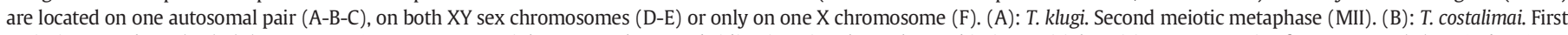

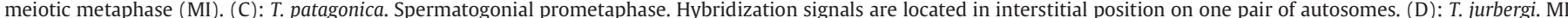

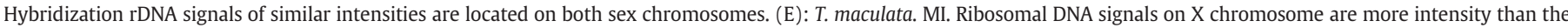
observed on the Y chromosome. (F): T. sordida sensu stricto. MI. Only one sex chromosome (X) shows rDNA clusters. Scale bar $=10 \mu \mathrm{m}$.

Another important consequence of the rDNA change from autosomes to sex chromosomes is the generation of new linkage groups in the X chromosomes. According to the available information in Diptera, controlling sex genes and reproduction-related traits genes are abundant on the $\mathrm{X}$ chromosomes, and many of them are involved in barriers to gene flow between diverging lineages (Noor and Feder, 2006). These genes, so-called "speciation" or "barrier" are related with reproductive isolation, including both pre-zygotic (such as pheromones) and postzygotic isolations (hybrid sterility and hybrid inviability) (for review see Qvarnström and Bailey, 2009). As a result of the insertion of the ribosomal genes it is likely that the formation of new linkage groups in the $\mathrm{X}$ chromosome establishes reproductive isolation among populations with different locations of the ribosomal genes. The translocation of ribosomal genes to sex chromosomes results in changes of the evolutionary dynamics and also has an effect on speciation. A hybrid resulting from a cross between two individuals with different localization of the rDNA loci (autosomes and sex chromosomes) produces unbalanced gametes in the number of rDNA loci resulting in reproductive disadvantage. Depending on the particular genotypes participating in a breeding, the combination of certain gametes could lead to a significant proportion of unviable zygotes (e.g., without rDNA clusters), selecting against heterozygotes and maintenance of polymorphisms in a population. These negative effects can be overcome if the two populations have fixed rDNA loci in both chromosomal positions. The simultaneous presence of rDNA loci in at least one sex chromosome and autosomes in reported in few species of Diptera (Roy et al., 2005), Coleoptera (Cabral de Mello et al., 2011) and Orthoptera (Cabrero and Camacho, 2008). In holocentric chromosomes, this double location is exceptional, having been reported only in two triatomine species: $T$. delpontei and $T$. infestans (Panzera et al., 2012, 2014). The last one exhibits an extensive
rDNA polymorphism involving more than one autosomal pair together with the X chromosome in their putative center of origin, but shows a strong tendency to fix the ribosomal clusters on the X chromosome during its dispersion process (Panzera et al., 2014). In conclusion, we propose that the rDNA translocation from the autosomes to the sex chromosomes limits reproductive compatibility and eventually promote speciation, similar as reported for other chromosomal rearrangements (Butlin, 2005). Perhaps the reverse movement of rDNA loci, i.e. from the sex chromosomes to autosomes is highly unlikely, given the new gene linkage relationships in the X chromosome and the establishment of isolation barriers to gene flow. Probably this mechanism may be acting on other insect groups, including with monocentric chromosomes such as Coleoptera, provided that the number of ribosomal clusters is present on one or two chromosomes per haploid complement.

\subsection{Phylogenetic relationships in Triatominae subcomplexes}

Triatominae species show high morphological plasticity which suggests that ecological factors may be the main force driving speciation in Triatominae (Dujardin et al., 1999). Very closely related species are able to develop rapid morphological changes in response to the adaptation to new environments. Conversely, similar morphs adapted to the same ecotope could be derived from different ancestors (Dujardin et al., 1999). Thus the existence of morphologically similar species could be reflecting both their evolution from a common ancestor or convergent adaptation to the same ecological niche. This phenotypic flexibility leads to misidentification of distinct genetic units by morphological convergence, arising taxonomic uncertainties in the description of new subspecies, species or even genera. Considering that the Triatominae species groupings in complexes and subcomplexes are 
mainly based on morphologically similarities (Schofield and Galvão, 2009), the morphological plasticity confused both species identification and the establishment of evolutionarily related groups.

Phylogenetic origin of blood-feeding Triatominae has received considerable attention due to the epidemiological significance as vectors of Chagas disease. Conflicting hypotheses support Triatominae as a monophyletic (Hypša et al., 2002; Patterson and Gaunt, 2010; Weirauch and Munro, 2009), polyphyletic (Schofield, 1988; Paula et al., 2005; Schofield and Galvão, 2009) or paraphyletic group (Hwang and Weirauch, 2012). Although that the monophyly or polyphyly of Triatoma genus is unclear, there is unanimity in considering that the South American Triatoma species (except T. melanocephala, $T$. tibiamaculata and T. vitticeps) constitute a monophyletic group (Hypša et al., 2002; Schofield and Galvão, 2009; Gardim et al., 2014; Justi et al., 2014).

Chromosomal differentiation in triatomines is mainly restricted to the variation of different repeated sequences, particularly the C-heterochromatin and ribosomal clusters (for reviews see Panzera et al., 2010, 2012). Cytogenetic analyses of more than 80 species reveal that most species which constitute each subcomplex share similar chromosomal characteristics, such as autosomal heterochromatin localization and rDNA clusters chromosomal position. Chromosomal change rate is very different among subcomplexes, some of them where species change rapidly (e.g., infestans subcomplex) and others where the species remain completely undifferentiated (e.g., phyllosoma subcomplex). Our working hypothesis is that the chromosomal location of major rDNA clusters is a species-specific character and evolutionary conserved trait, so that closely related species tend to have the major ribosomal clusters in the same chromosomal location.

In this paper, considering the ribosomal clusters chromosomal location by FISH and in the light of the available molecular data, we have evaluated the species integration of maculata, matogrossensis, rubrovaria and sordida subcomplexes, and propose new arrangements that reflect their evolutionary relationships more accurately.

\subsubsection{Rubrovaria subcomplex}

It includes seven species that share morphological characteristics and geographical distribution (southern Brazil, Uruguay and Northwestern Argentina): T. rubrovaria, T. carcavalloi, T. circummaculata, $T$. klugi, T. limai and T. oliveirai (Schofield and Galvão, 2009). Recently, T. pintodiasi was described and incorporated in this subcomplex due to its close morphological, morphometric and biochemical (hemolymph proteins) similarities (Jurberg et al., 2013).

Several morphometric and molecular analyses show close evolutionary relationships among $T$. carcavalloi, $T$. circummaculata, T. klugi and T. rubrovaria (García et al., 2001; Hypša et al., 2002; Sainz et al., 2004; Paula et al., 2005; Almeida et al., 2009, Gardim et al., 2014). Morphometric similarities between $T$. klugi and $T$. oliveirai were reported by Noireau et al. (2002). Membership in this subcomplex of T. limai, T. oliveirai and $T$. pintodiasi must be confirmed as there are no molecular data on these 3 species.

Our FISH results show that all rubrovaria species analyzed hitherto present the ribosomal clusters on an autosomal pair (Tables 1 and 2), confirming their close phylogenetic relationships. Furthermore, two other species belonging to sordida subcomplex show the same chromosome location: T. guasayana and T. patagonica (Table 1). Analyses of several nuclear and mitochondrial fragments also cluster these two species in the same clade within rubrovaria subcomplex (García et al., 2001; Hypša et al., 2002; Sainz et al., 2004; Paula et al., 2005; Almeida et al., 2009; Gardim et al., 2014). The close association among T. sordida and T. guasayana observed in phylogenetic trees with COI and Cyt b fragments reported by Gardim et al. (2013) and Justi et al. (2014) probably are due to an incorrect identification of the analyzed specimens since to their great morphological similarity, as has been suggested by Panzera et al. (2015).
Table 2

New proposal of South American Triatoma species involving maculata, matogrossensis, rubrovaria and sordida subcomplexes previously grouping by Schofield and Galvão (2009)

\begin{tabular}{|c|c|c|}
\hline $\begin{array}{l}\text { Subcomplex proposed by } \\
\text { Schofield \& Galvão (2009) }\end{array}$ & Our new proposal & $\begin{array}{l}\text { Chromosomal } \\
\text { localization of } \\
\text { ribosomal } \\
\text { clusters }\end{array}$ \\
\hline $\begin{array}{l}\text { Rubrovaria: } T \text {. carcavalloi, } T \text {. } \\
\text { circummaculata, T. klugi, T. } \\
\text { limai, T. oliveirai, T. } \\
\text { rubrovaria }\end{array}$ & 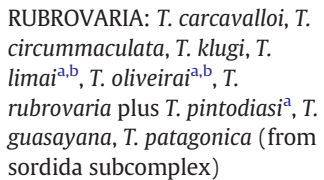 & $\begin{array}{l}\text { One autosomal } \\
\text { pair }\end{array}$ \\
\hline $\begin{array}{l}\text { Matogrossensis: } T \text {. baratai, } T \text {. } \\
\text { costalimai, } T \text {. deaneorum, } T \text {. } \\
\text { guazu, } T \text {. jurbergi, } T \text {. } \\
\text { matogrossensis, } T \text {. vandae, } T \text {. } \\
\text { williami. }\end{array}$ & ELIMINATED & \\
\hline $\begin{array}{l}\text { Sordida: } T \text {. garciabesi, } T \text {. } \\
\text { guasayana, T. patagonica, } T \text {. } \\
\text { sordida. }\end{array}$ & $\begin{array}{l}\text { SORDIDA: T. garciabesi, } T \text {. } \\
\text { sordida, T. sordida Argentina } \\
\text { (new species) plus T. jurbergi, } \\
\text { T. matogrossensis, T. vandae } \\
\text { (from matogrossensis } \\
\text { subcomplex) }\end{array}$ & $\begin{array}{l}\text { One }(\mathrm{X}) \text { or two } \\
\text { sex } \\
\text { chromosomes } \\
(\mathrm{XY})\end{array}$ \\
\hline \multirow{2}{*}{$\begin{array}{l}\text { Maculata: } T \text {. arthurneivai, } T \text {. } \\
\text { maculata, } T . \\
\text { pseudomaculata, } T \text {. } \\
\text { wygodzinskyi. }\end{array}$} & MACULATA: T. maculata & $\begin{array}{l}\text { Sex } \\
\text { chromosomes } \\
(\mathrm{XY})\end{array}$ \\
\hline & $\begin{array}{l}\text { NEW SUBCOMPLEX: } \\
\text { PSEUDOMACULATA or } \\
\text { ARTHURNEIVAI: } T \text {. } \\
\text { arthurneivai }^{\mathrm{a}, \mathrm{b}}, T \text {. } \\
\text { pseudomaculata, } T \text {. } \\
\text { wygodzinskyi plus } T \text {. baratai, } T \text {. } \\
\text { costalimai, } T \text {. deaneorum }{ }^{\mathrm{a}, \mathrm{b}}, T \text {. } \\
\text { guazu, } T \text {. jatai, } T \text {. } \text { williami (from }_{\text {matogrossensis subcomplex) }}\end{array}$ & $\begin{array}{l}\text { One autosomal } \\
\text { pair }\end{array}$ \\
\hline
\end{tabular}

\footnotetext{
Molecular data unknown.

b FISH data unknown.
}

In brief, considering all genetic data available and the similar ribosomal clusters location, we proposed that the rubrovaria subcomplex would be constituted by the following species: T. carcavalloi, $T$. circummaculata, T. guasayana, T. klugi, T. limai, T. oliveirai, T. patagonica, T. pintodiasi and T. rubrovaria.

\subsubsection{Maculata subcomplex}

Currently, this subcomplex is constituted by four species: $T$. maculata, T. pseudomaculata, T. arthurneivai and T. wygodzinskyi (Schofield and Galvão, 2009). These species are extremely similar and cannot be easily distinguished considering external characters alone. However, their ecological behavior is very different; the first two are arboreal while the latter are rupicolous (Lent and Wygodzinsky, 1979). Geometric morphometric analyses on wings suggested a misidentification between T. arthurneivai and T. wygodzinskyi (Carbajal de la Fuente et al., 2010). For this reason all published genetic data on T. arthurneivai must correspond to T. wygodzinskyi. T. arthurneivai would be restricted to Sierra do Cipó (Minas Gerais, Brazil) and no genetic data are available.

According to Schofield (1988), T. maculata and T. pseudomaculata resulted from the evolution of two geographic populations derived from a common ancestor. Our FISH results clearly splits the maculata subcomplex in two clades: species with the ribosomal genes in an autosomal pair (T. pseudomaculata and T. wygodzinskyi) and a species having the ribosomal genes in both sex chromosomes (T. maculata) (Table 1, Fig. 1). This clear division (T. maculata vs T. pseudomaculata/T. wygodzinskyi) and the close evolutionary relationship between $T$. pseudomaculata and T. wygodzinskyi were also been reported by isoenzymes (Dos Santos et al., 2007), nuclear (Bargues et al., 2008; Justi et al., 2014) and mitochondrial sequences (Hypša et al., 2002; Paula et 
al., 2005; Justi et al., 2014). Genetic similarity between T. maculata and $T$. pseudomaculata is only reported by two papers (Sainz et al., 2004; Gardim et al., 2014). In the first paper the similarity between both species is due to a species misidentification, considering that $T$. maculata is not distributed in Sergipe (Brazil) (AF324512/AF324524). Same issue is probably happening with the specimens used by Gardim et al. (2014) which are from an unknown origin and at least 30 years old insectary colony.

In brief, unlike Schofield (1988) proposal, genetic data including our FISH results strongly suggest that T. maculata and T. pseudomaculata/T. wygodzinskyi not derived from a recent common ancestor and are evolutionarily distinct units. We propose the formation of a new subcomplex provisionally named Pseudomaculata including $T$. pseudomaculata and T. wygodzinskyi (Table 2) along with other species (see below). Molecular analyses on T. arthurneivai should determine whether this species belongs to maculata or pseudomaculata subcomplexes. In the latter case the new subcomplex will be called arthurneivai since as it would be the first species originally described. Considering the similar geographical distribution and habits of both species, probably T. arthurneivai is close to T. wygodzinskyi. On the other hand, we proposed that T. maculata constituted a separated subcomplex formed only by this species. Phylogenetic trees positioned this species alone and in a basal position within South American Triatoma (Hypša et al., 2002; Paula et al., 2005; Justi et al., 2014).

\subsubsection{Matogrossensis subcomplex}

Includes nine species which share morphological characteristics, all terrestrial and distributed throughout the Pantanal ecosystem in Central-Western Brazil and Paraguay: T. baratai, T. costalimai, T. deaneorum, T. guazu, T. jurbergi, T. matogrossensis, T. vandae and T. williami (Schofield and Galvão, 2009). Recently, T. jatai was described and incorporated in the matogrossensis subcomplex due to its close morphological, morphometric and genetic similarities with T. costalimai (Gonçalves et al., 2013; Teves et al., 2016). Molecular data of T. deaneorum are not available.

None DNA sequences analysis succeeded to recover a clade formed by matogrossensis subcomplex species, reflecting a conflict between ecologic and genetic data (Hypša et al., 2002; Sainz et al., 2004; Paula et al., 2005; Gardim et al., 2013; Justi et al., 2014; Teves et al., 2016). Our FISH results clearly splits the matogrossensis subcomplex in two clusters: species with the ribosomal genes on an autosomal pair ( $T$. baratai, T. costalimai, T. guazu, T. jatai and T. williami), and species bearing the ribosomal clusters on both sex chromosomes ( $T$. jurbergi, $T$. matogrossensis and T. vandae) (Table 1, Fig. 1). A same dichotomy was also reported by morphometry (eight measurements of head and thorax) and isoenzyme (18 loci) analyses (Noireau et al., 2002) on the former called "T. oliveirai complex" (Carcavallo et al., 2001) currently matogrossensis subcomplex. Several analyses with mitochondrial genes (mainly $12 \mathrm{~S}$ and $16 \mathrm{~S}$ rDNA) have shown that $T$. jurbergi, $T$. matogrossensis and T. vandae are closely related among them and with sordida species (T. sordida and T. garciabesi) (García et al., 2001; Hypša et al., 2002; Sainz et al., 2004; Paula et al., 2005; Gardim et al., 2013; Justi et al., 2014; Teves et al., 2016). All these species showed the rDNA clusters on one or two sex chromosomes (Table 1). In conclusion, considering all available genetic data and the similar ribosomal clusters localization (all bearing ribosomal genes on sex chromosomes, either both or just the $\mathrm{X}$ chromosome), we proposed that the sordida subcomplex must be constituted by the following species: T. garciabesi, T. sordida, T. sordida Argentina (putative new species suggested by Panzera et al., 2015) plus T. jurbergi, T. matogrossensis and T. vandae (from matogrossensis subcomplex). From this subcomplex we excluded T. guasayana and T. patagonica which has been proved to be related with the rubrovaria subcomplex (Table 2 ).

In the other matogrossensis subcomplex subdivision, constituted by T. baratai, T. costalimai, T. guazu and T. williami, their phylogenetic relationships among them are not clear, particularly the position of $T$. costalimai. In this species, molecular analyses of different mitochondrial genes ( $\mathrm{COI}$, COII and cyt b) performed on individuals from Brazil and Bolivia (numbers 35 and 42, respectively) show very large genetic distances (over 8.3\%), which reveals an incorrect species identification in at least one of the specimens analyzed by Justi et al. (2014).

Isoenzyme and morphometric analyses clearly indicate a lack of differentiation between T. guazu and T. williami (Noireau et al., 2002). DNA sequence comparison between these two species of all mitochondrial fragments available in GenBank (12S, 16S, COI, COII and Cyt b) reveals nucleotide differences not exceeding $1.8 \%$ (data not showed), similar as observed among conspecific populations. All this information, along with a similar geographic distribution (Mato Grosso, Brazil), questions the existence of T. guazu and T. williami as two separate species.

Our FISH results in T. baratai, T. costalimai, T. guazu, T. jatai and $T$. williami (from matogrossensis subcomplex) as well as in $T$. pseudomaculata and T. wygodzinskyi (from maculata subcomplex) showed that the ribosomal clusters are localized on one autosomal pair. Evolutionary relationships between these two groups of species are not constant, and vary according to the specimens used and the molecular markers analyzed (Gardim et al., 2013). These inconsistencies clearly reveal improper sequencing or misidentification of species, such as above mentioned for T. costalimai. In spite of this, several phylogenetic trees, mainly with $12 \mathrm{~S}$ and $16 \mathrm{~S}$ fragments, show a close association among the two species groups afore mentioned (Hypša et al., 2002; Paula et al., 2005; Justi et al., 2014).

In summary, considering the available genetic data and the similar ribosomal clusters localization, we propose the inclusion of $T$. baratai, T. costalimai, T. deaneorum, T. guazu, T. jatai and T. williami within the same subcomplex that T. pseudomaculata and T. wygodzinskyi (Table 2).

\section{Conclusions}

We suggest that the movement of rDNA loci from autosomes to sex chromosomes rapidly established reproductive barriers between divergent lineages in triatomines. The same chromosomal location of the ribosomal genes reveals evolutionarily close species with a common ancestor. Since these changes can occur several times independently in distant triatomine groups, it is necessary to contrast the evolutionary relationships obtained with rDNA location with phylogenetic markers, such as the sequence comparisons of nuclear and mitochondrial genes. Based on these assumptions, we propose a reordering of species that composed several subcomplexes of Triatoma from South America.

\section{Acknowledgements}

This work was supported by project grants (no. 370) from the “Comisión Sectorial de Investigación Científica” (CSIC-Udelar-Uruguay), Programa de Desarrollo de las Ciencias Básicas (PEDECIBA Uruguay), Agencia Nacional de Investigación e Innovación (ANII, Uruguay), Fundação de Amparo a Pesquisa do Estado de São Paulo (FAPESP-Brazil) (Processo $n^{\circ}$ 13/19764-0) and by the "Conserjería de Innovación, Ciencia y Empresa de la Junta de Andalucía”, sponsor of Program of Academic Mobility of AUIP (Ibero-American University Postgraduate Association) for SP and FP. This paper is included in the Ph.D. Thesis of Sebastián Pita (Udelar-University of Jaén).

\section{References}

Almeida, C.E., Marcet, P.L., Gumiel, M., Takiya, D.M., Cardozo-de-Almeida, M., Pacheco R.S., Lopes, C.M., Dotson, E.M., Costa, J., 2009. Phylogenetic and phenotypic relationships among Triatoma carcavalloi (Hemiptera: Reduviidae: Triatominae) and related species collected in domiciles in Rio Grande do Sul state, Brazil. J. Vector Ecol. 34, 164-173.

Bardella, V.B., Gaeta, M.L., Vanzela, A.L., Azeredo-Oliveira, M.T., 2010. Chromosomal location of heterochromatin and 45S rDNA sites in four South American triatomines (Heteroptera: Reduviidae). Comp. Cytogenet. 4, 141-149.

Bargues, M.D., Klisiowicz, D.R., Gonzalez-Candelas, F., Ramsey, J.M., Monroy, C., Ponce, C. Salazar-Schettino, P.M., Panzera, F., Abad-Franch, F., Sousa, O.E., Schofield, C.J., 
Dujardin, J.P., Guhl, F., Mas-Coma, S., 2008. Phylogeography and genetic variation of Triatoma dimidiata, the main Chagas' disease vector in Central America, and its position within the genus Triatoma. PLoS Negl. Trop. Dis. 2, e233.

Bressa, M.J., Papeschi, A.G., Vítková, M., Kubíčková, S., Fuková, I., Pigozzi, M.I., Marec, F. 2009. Sex chromosome evolution in cotton stainers of the genus Dysdercus (Heteroptera: Pyrrhocoridae). Cytogenet. Genome Res. 125, 292-305.

Butlin, R.K., 2005. Recombination and speciation. Mol. Ecol. 14, 2621-2635.

Cabral-de-Mello, D.C., Oliveira, S.G., Moura, R.C., Martins, C., 2011. Chromosomal organization of the $18 \mathrm{~S}$ and $5 \mathrm{~S}$ rRNAs and histone $\mathrm{H3}$ genes in Scarabaeinae coleopterans: insights into the evolutionary dynamics of multigene families and heterochromatin. BMC Genet. 12, 88 .

Cabrero, J., Camacho, J.P.M., 2008. Location and expression of ribosomal RNA genes in grasshoppers: abundance of silent and cryptic loci. Chromosom. Res. 16, 595-607.

Carbajal de la Fuente, A.L., Noireau, F., Catalá, S.S., 2008. Inferences about antennal phenotype: the "Triatoma maculata complex" (Hemiptera: Triatominae) is valid? Acta Trop. $106,16-21$.

Carbajal de la Fuente, A.L., Jaramillo, N., Barata, J.M.S., Noireau, F., Diotaiuti, L., 2010. Misidentification of two Brazilian triatomes, Triatoma arthurneivai and Triatoma wygodzinskyi, revealed by geometric morphometrics. Med. Vet. Entomol. 25, 178-183.

Carcavallo, R.U., Jurberg, J., Lent, H., Noireau, F., Galvão, C., 2000. Phylogeny of the Triatominae (Hemiptera Reduviidae). Proposals for taxonomic arrangements. Entomol. Vectores 7, 1-99.

Carcavallo, R.U., Jurberg, J., Lent, H., Galvão, C., Steindel, M., Pinto, C.J., 2001. Nova espécie do complexo oliveirai (nova denominação para o complexo matogrossensis (Hemiptera, Reduviidae, Triatominae) do Estado do Rio Grande do Sul, Brasil. Mem. Inst. Oswaldo Cruz 96, 71-79.

Dos Santos, S.M., Lopes, C.M., Dujardin, J.P., Panzera, F., Pérez, R., Carbajal de la Fuente, A.L., Pacheco, R.S., Noireau, F., 2007. Evolutionary relationships based on genetic and phenetic characters between Triatoma maculata, Triatoma pseudomaculata and morphologically related species (Reduviidae: Triatominae). Infect. Genet. Evol. 7, 469-475.

Dujardin, J.P., Panzera, P., Schofield, C.J., 1999. Triatominae as a model of morphological plasticity under ecological pressure. Mem. Inst. Oswaldo Cruz 94, 223-238.

Galvão, C., Paula, A.S., 2014. Sistemática e evolução dos vetores. In: Galvão, C. (Org.), Vetores da doença de Chagas no Brasil [online], Chapter 3, Sociedade Brasileira de Zoologia. doi: 10.7476/9788598203096. pp. 26-32.

García, B.A., Moriyama, E.N., Powell, J.R., 2001. Mitochondrial DNA sequences of triatomines (Hemiptera: Reduviidae): phylogenetic relationships. J. Med. Entomol $38,675-683$.

Gardim, S., Rocha, C.S., Almeida, C.E., Takiya, D.M., Silva, M.T.A., Ambrósio, D.L., Cicarelli, R.M.B., Rosa, J.A., 2013. Evolutionary relationships of the Triatoma matogrossensis subcomplex, the endemic Triatoma in Central-Western Brazil, based on mitochondrial DNA sequences. Am.J.Trop. Med. Hyg. 89, 766-774.

Gardim, S., Almeida, C.E., Takiya, D.M., Oliveira, J., Araújo, R.F., Cicarelli, R.M.B., Rosa, J.A 2014. Multiple mitochondrial genes of some sylvatic Brazilian Triatoma: non-monophyly of the $T$. brasiliensis subcomplex and the need for a generic revision in the Triatomini. Infect. Genet. Evol. 23, 74-79.

Gonçalves, T.C.M., Teves-Neves, S.C., dos Santos-Mallet, J.R., Carbajal-de-la-Fuente, A.L., Lopes, C.M., 2013. Triatoma jatai sp. nov. in the state of Tocantins, Brazil (Hemiptera: Reduviidae: Triatominae). Mem. Inst. Oswaldo Cruz 108, 429-437.

Grozeva, S., Anokhin, B.A., Kuznetsova, V.G., 2015. Bedbugs (Hemiptera). In: Sharakhov I.V. (Ed.), Protocols for Cytogenetic Mapping of Arthropod Genomes, Chapter 8. CRC Press, Boca Raton, pp. 285-326.

Hirai, H., Yamamoto, M.T., Taylor, R.W., Imai, H.T., 1996. Genomic dispersion of 28S rDNA during karyotypic evolution in the ant genus Myrmecia (Formicidae). Chromosoma 105, 190-196.

Hughes-Schrader, S., Schrader, F., 1961. The kinetochore of the Hemiptera. Chromosoma 12, 327-350.

Hwang, W.S., Weirauch, C., 2012. Evolutionary history of assassin bugs (Insecta: Hemiptera: Reduviidae): insights from divergence dating and ancestral state reconstruction. PLoS One 7, e45523.

Hypša, V., Tietz, D.F., Zrzavý, J., Rego, R.O.M., Galvão, C., Jurberg, J., 2002. Phylogeny and biogeography of Triatominae (Hemiptera: Reduviidae): molecular evidence of a new world origin of the Asiatic clade. Mol. Phylogenet. Evol. 23, 447-457.

ICZN (International Code of Zoological Nomenclature), 1999. Fourth edition. American Association for Zoological Nomenclature (ed.). London, (306 pp).

Jurberg, J., Cunha, V., Cailleaux, S., Raigorodschi, R., Lima, M.S., Rocha, D.S., Moreira, F.F. 2013. Triatoma pintodiasi sp. nov. do subcomplexo T. rubrovaria (Hemiptera, Reduviidae, Triatominae). Rev. Pan-Amaz Saude 4, 43-56.

Justi, S.A., Russo, C.A.M., Mallet, J.R.S., Obara, M.T., Galvão, C., 2014. Molecular phylogeny of Triatomini (Hemiptera: Reduviidae: Triatominae). Parasit. Vectors 7, 149.

Kaiser, V.B., Bachtrog, D., 2010. Evolution of sex chromosomes in insects. Annu. Rev. Genet. 44, 91-112.
Lent, H., Wygodzinsky, P., 1979. Revision of the Triatominae (Hemiptera, Reduviidae), and their significance as vectors of Chagas's disease. Bull. Am. Mus. Nat. Hist. 163, 123-520.

Nguyen, P., Sahara, K., Yoshido, A., Marec, F., 2010. Evolutionary dynamics of rDNA clusters on chromosomes of moths and butterflies (Lepidoptera). Genetica 138, 343-354.

Noireau, F., Menezes, S., Gumiel, M., Dujardin, J.P., Santos Soares, R.U., Galvão, C., Jurberg, J., 2002. Phylogenetic relationships within the Oliveirai complex (Hemiptera: Reduviidae: Triatominae). Infect. Genet. Evol. 2, 11-17.

Noor, M.A.F., Feder, J.L., 2006. Speciation genetics: evolving approaches. Nat. Rev. Genet. 7, 851-861.

Panzera, F., Hornos, S., Pereira, J., Cestau, R., Canale, D., Diotaiuti, L., Dujardin, J.P., Pérez, R., 1997. Genetic variability and geographic differentiation among three species of triatomine bugs (Hemiptera-Reduviidae). Am.J.Trop. Med. Hyg. 57, 732-739.

Panzera, F., Pérez, R., Panzera, Y., Ferrandis, I., Ferreiro, M.J., Calleros, L., 2010. Cytogenetics and genome evolution in the subfamily Triatominae (Hemiptera, Reduviidae). Cytogenet. Genome Res. 128, 77-87.

Panzera, F., Ferreiro, M.J., Pita, S., Calleros, L., Pérez, R., Basmadjián, Y., Guevara, Y., Brenière, S.F., Panzera, Y., 2014. Evolutionary and dispersal history of Triatoma infestans, main vector of chagas disease, by chromosomal markers. Infect. Genet. Evol. 27, 105-113.

Panzera, F., Pita, S., Nattero, J., Panzera, Y., Galvão, C., Chavez, T., Rojas De Arias, A., Cardozo Téllez, L., Noireau, F., 2015. Cryptic speciation in the Triatoma sordida subcomplex (Hemiptera, Reduviidae) revealed by chromosomal markers. Parasit. Vectors 8, 495.

Panzera, Y., Pita, S., Ferreiro, M.J., Ferrandis, I., Lages, C., Pérez, R., Silva, A.E., Guerra, M., Panzera, F., 2012. High dynamics of rDNA cluster location in kissing bug holocentric chromosomes (Triatominae, Heteroptera). Cytogenet. Genome Res. 138, 56-67.

Patterson, J.S., Gaunt, M.W., 2010. Phylogenetic multi-locus codon models and molecular clocks reveal the monophyly of haematophagous reduviid bugs and their evolution at the formation of South America. Mol. Phylogenet. Evol. 56, 608-621.

Paula, A.S., Diotaiuti, L., Schofield, C.J., 2005. Testing the sister-group relationship of the Rhodniini and Triatomini (Insecta: Hemiptera: Reduviidae: Triatominae). Mol. Phylogenet. Evol. 35, 712-718.

Proença, S.J.R., Collares-Pereira, M.J., Serrano, A.R.M., 2005. Chromosome evolution in tiger beetles: karyotypes and localization of 18S rDNA loci in Neotropical Megacephalini (Coleoptera, Cicindelidae). Genet. Mol. Biol. 28, 725-733.

Qvarnström, A., Bailey, R.I., 2009. Speciation through evolution of sex-linked genes. Heredity $102,4-15$

Richard, G.-F., Kerrest, A., Dujon, B., 2008. Comparative genomics and molecular dynamics of DNA repeats in eukaryotes. Microbiol. Mol. Biol. Rev. 72, 686-727.

Roy, V., Monti-Dedieu, L., Chaminade, N., Siljak-Yakovlev, S., Aulard, S., Lemeunier, F., Montchamp-Moreau, C., 2005. Evolution of the chromosomal location of rDNA genes in two Drosophila species subgroups: ananassae and melanogaster. Heredity 94, 388-395.

Ryckman, R.E., 1962. Biosystematics and hosts of the Triatoma protracta complex in North America. Univ. Calif. Publ. Entomol. 27, 93-239.

Sætre, G.P., Borge, T., Lindroos, K., Haavie, J., Sheldon, B.C., Primmer, C., Syvänen, A.C., 2003. Sex chromosome evolution and speciation in Ficedula flycatchers. Proc. R. Soc. London B 270, 53-59.

Sainz, A.C., Mauro, L.V., Moriyama, E.N., García, B.A., 2004. Phylogeny of triatomine vectors of Trypanosoma cruzi suggested by mitochondrial DNA sequences. Genetica 121, 229-240.

Schofield, C.J., 1988. Biosystematics of the Triatominae. In: Service, M.W. (Ed.), Biosystematic of Haematophagous Insects Vol. 37. Clarendon Press, Oxford, pp. 284-312

Schofield, C.J., Galvão, C., 2009. Classification, evolution and species groups within the Triatominae. Acta Trop. 110, 88-100

Šíchová, J., Nguyen, P., Dalíková, M., Marec, F., 2013. Chromosomal evolution in tortricid moths: conserved karyotypes with diverged features. PLoS One 8, e64520.

Solari, A.J., 1979. Autosomal synaptonemal complexes and sex chromosomes without axes in Triatoma infestans (Reduviidae; Hemiptera). Chromosoma 72, 225-240.

Teves, S.C., Gardim, S., Carbajal de la Fuente, A.L., Lopes, C.M., Gonçalves, T.C.M., dos Santos Mallet, J.R., da Rosa, J.A., Almeida, C.E., 2016. Mitochondrial genes reveal Triatoma jatai as a sister species to Triatoma costalimai (Reduviidae: Triatominae). Am.J.Trop. Med. Hyg. 94, 686-688.

Usinger, R.L., Wygodzinsky, P., Ryckman, R.E., 1966. The biosystematics of Triatominae. Annu. Rev. Entomol. 11, 309-330.

Vicoso, B., Charlesworth, B., 2006. Evolution on the X chromosome: unusual patterns and processes. Nat. Rev. Genet. 7, 645-653.

Weirauch, C., Munro, J.B., 2009. Molecular phylogeny of the assassin bugs (Hemiptera: Reduviidae), based on mitochondrial and nuclear ribosomal genes. Mol. Phylogenet. Evol. 53, 287-299.

WHO (World Health Organization), 2016. Chagas disease (American trypanosomiasis). (Available:) http://www.who.int/mediacentre/factsheets/fs340/en/index.html. 